\title{
Validation and clinical application of a targeted next- generation sequencing gene panel for solid and hematologic malignancies
}

\author{
Iván Prieto-Potin ${ }^{1}$, Nerea Carvajal ${ }^{1}$, Jenifer Plaza-Sánchez ${ }^{1}$, Rebeca Manso $^{1}$, Carmen Laura Aúz Alexandre ${ }^{1}$, \\ Cristina Chamizo ${ }^{1}$, Sandra Zazo ${ }^{1}$, Almudena López-Sánchez ${ }^{1}$, Socorro María Rodríguez-Pinilla ${ }^{1}$, Laura Camacho ${ }^{2}$, \\ Raquel Longarón ${ }^{2}$, Beatriz Bellosillo ${ }^{2}$, Rosa Somoza ${ }^{3}$, Javier Hernández-Losa ${ }^{3}$, Víctor Manuel Fernández-Soria ${ }^{4}$, \\ Ricardo Ramos-Ruiz ${ }^{4}$, Ion Cristóbal ${ }^{5}$, Jesús García-Foncillas ${ }^{5}$, Federico Rojo ${ }^{\text {Corresp. } 1}$ \\ ${ }^{1}$ Department of Pathology, CIBERONC, UAM, Fundación Jiménez Díaz University Hospital Health Research Institute, Madrid, Spain \\ 2 Department of Pathology, Hospital Del Mar Medical Research Institute, Barcelona, Spain \\ 3 Department of Pathology, Vall d'Hebron University Hospital, Barcelona, Spain \\ 4 Genomics Unit, Madrid Science Park, Cantoblanco, Madrid, Spain \\ 5 Translational Oncology Division, UAM, Fundación Jiménez Díaz University Hospital Health Research Institute, Madrid, Spain \\ Corresponding Author: Federico Rojo \\ Email address: frojo@fjd.es
}

Background: Next-generation sequencing (NGS) is a high-throughput technology that has become widely integrated in molecular diagnostics laboratories. Among the large diversity of NGS-based panels, the Trusight Tumor 26 (TsT26) enables the detection of lowfrequency variants across 26 genes using the MiSeq platform. Methods: We describe the inter-laboratory validation and subsequent clinical application of the panel in 399 patients presenting a range of tumor types, including gastrointestinal (GI,29\%), hematologic (18\%), lung (13\%), gynecological and breast (8\% each), among others. Results: The panel is highly accurate with a test sensitivity of $92 \%$, and demonstrated high specificity and positive predictive values (95\% and $96 \%$, respectively). Sequencing testing was successful in two-thirds of patients, while the remaining third failed due to unsuccessful qualitycontrol filtering. Most detected variants were observed in the TP53 (28\%), KRAS (16\%), APC (10\%) and PIK3CA (8\%) genes. Overall, 372 variants were identified, primarily distributed as missense (81\%), stop gain (9\%) and frameshift (7\%) altered sequences and mostly reported as pathogenic (78\%) and variants of uncertain significance (19\%). Only $14 \%$ of patients received targeted treatment based on the variant determined by the panel. The variants most frequently observed in $\mathrm{Gl}$ and lung tumors were: KRASc.35G >A (p.G12D), c.35G>T (p.G12V) and c.34G>T (p.G12C). Conclusions: Prior panel validation allowed its use in the laboratory daily practice by providing several relevant and potentially targetable variants across multiple tumors. However, this study is limited by high sample inadequacy rate, raising doubts as to continuity in the clinical setting. 
1 Validation and clinical application of a targeted next-generation sequencing gene panel for

2 solid and hematologic malignancies

3 Iván Prieto-Potin ${ }^{1}$, Nerea Carvajal ${ }^{1}$, Jenifer Plaza-Sánchez ${ }^{1}$, Rebeca Manso ${ }^{1}$, Carmen Laura Aúz

4 Alexandre ${ }^{1}$, Cristina Chamizo ${ }^{1}$, Sandra Zazo $^{1}$, Almudena López-Sánchez ${ }^{1}$, Socorro María

5 Rodríguez-Pinilla ${ }^{1}$, Laura Camacho², Raquel Longarón ${ }^{2}$, Beatriz Bellosillo², Rosa Somoza ${ }^{3}$, Javier

6 Hernández-Losa ${ }^{3}$, Víctor Manuel Fernández-Soria ${ }^{4}$, Ricardo Ramos-Ruiz ${ }^{4}$, Ion Cristóbal ${ }^{5}$, Jesús

7 García-Foncillas ${ }^{5}$, Federico Rojo ${ }^{1}$

$8{ }^{1}$ Molecular Diagnostics Laboratory, Department of Pathology, CIBERONC, Fundación Jiménez

9 Díaz University Hospital Health Research Institute, Autonomous University of Madrid, Madrid,

10 Spain.

112 Department of Pathology, Hospital Del Mar, Hospital Del Mar Medical Research Institute,

12 Barcelona, Spain.

$13{ }^{3}$ Department of Pathology, Vall d'Hebron University Hospital, Barcelona, Spain.

$14{ }^{4}$ Genomics Unit, Madrid Science Park, Cantoblanco, Madrid, Spain

155 Translational Oncology Division, Fundación Jiménez Díaz University Hospital Health

16 Research Institute, Autonomous University of Madrid, Madrid, Spain.

17 Corresponding author: Federico Rojo, M.D., Ph.D., Department of Pathology, IIS-Fundación

18 Jiménez Díaz, UAM, Madrid 28040, Spain. E-mail: frojo@,fjd.es, ORCID:

19 https://orcid.org/0000-0001-9989-0290 
21 Keywords: next-generation sequencing, validation, cancer, solid tumor, hematologic

22 malignancies

23 Background: Next-generation sequencing (NGS) is a high-throughput technology that has become 24 widely integrated in molecular diagnostics laboratories. Among the large diversity of NGS-based 25 panels, the Trusight Tumor 26 (TsT26) enables the detection of low-frequency variants across 26 26 genes using the MiSeq platform.

Methods: We describe the inter-laboratory validation and subsequent clinical application of the panel in 399 patients presenting a range of tumor types, including gastrointestinal (GI, 29\%), hematologic (18\%), lung (13\%), gynecological and breast ( $8 \%$ each), among others.

Results: The panel is highly accurate with a test sensitivity of $92 \%$, and demonstrated high specificity and positive predictive values (95\% and $96 \%$, respectively). Sequencing testing was successful in two-thirds of patients, while the remaining third failed due to unsuccessful qualitycontrol filtering. Most detected variants were observed in the TP53 (28\%), KRAS (16\%), APC (10\%) and PIK3CA (8\%) genes. Overall, 372 variants were identified, primarily distributed as missense (81\%), stop gain (9\%) and frameshift (7\%) altered sequences and mostly reported as pathogenic (78\%) and variants of uncertain significance (19\%). Only $14 \%$ of patients received targeted treatment based on the variant determined by the panel. The variants most frequently observed in GI and lung tumors were: KRAS c.35G $>$ A (p.G12D), c.35G $>$ T (p.G12V) and c.34G $>$ T (p.G12C).

Conclusions: Prior panel validation allowed its use in the laboratory daily practice by providing several relevant and potentially targetable variants across multiple tumors. However, this study is

42 limited by high sample inadequacy rate, raising doubts as to continuity in the clinical setting. 
Introduction

Most molecular diagnostics laboratories have incorporated next-generation sequencing

47 (NGS) technology, which allows high-throughput sequencing of the genome. This machinery has

48

49

50

51

52

been introduced in part to meet the need of clinicians to gather data on genetic alterations and precisely guide decisions on specific molecular-based therapy approaches for individual patients (Friedman et al., 2015). The substantial cost-effectiveness and multiple advantages of NGS over other technologies may explain its widespread use (Tan et al., 2018). One single assay of NGS testing allows simultaneous screening of multiple genes in numerous samples in comparison to the rest of diagnostic platforms that generally analyze an individual gene of a unique sample. NGS is a highly sensitive tool requiring small amounts of DNA input to provide variant allele frequencies (Luthra et al., 2015; Surrey et al., 2016).

Molecular profiling of tumoral DNA is a key attribute of massive sequencing that permits the identification of only a few driver or resistance mutations required for the administration of accurate treatments (Morganti et al., 2019). Hence, platforms analyzing a single marker are becoming obsolete as laboratory teams opt for techniques that yield results from several markers at once. An NGS-based gene panel test can be used to detect genetic aberrations in different biomarkers that can be targeted by molecular-based drugs (Nagahashi et al., 2018). Accordingly, the development of distinct gene panels enables identification of multiple mutations of a particular tumor type. In lung cancer, alterations in the EGFR, $A L K$ or ROS1 genes are used to guide FDAapproved therapies (Hyman, Taylor \& Baselga, 2017). Among the many NGS-based panel types, 
65 the Trusight Tumor 26 (TsT26) by Illumina uses a small actionable gene panel facilitating the

66

67 identification of low-frequency variants of genes involved in targeted therapy for solid tumors (Dong et al., 2015). The panel included the KRAS, NRAS and BRAF genes that may be used to determine the eligibility of colorectal cancer (CRC) patients for targeted anti-EGFR treatment, as well as to establish prognosis at any stage of the disease (Sepulveda et al., 2017). Several guidelines and recommendations have been published to standardize the implementation of NGSbased panels in the clinical setting by means of prior technical validation (Jennings et al., 2017). An NGS-based panel should not be set up in a clinical practice unless an acceptable validation is performed beforehand (Matthijs et al., 2016). In fact, the validation process should thoroughly document how the assay is reliable in identifying known mutations detected by diagnostic standards (McCourt et al., 2013).

After multidisciplinary clinical consensus was reached, it became clear that an NGS-based panel would be needed in routine medical care for detailed molecular characterization of patients presenting a range of advanced cancer types. A unique molecular testing could satisfy the demand by considering either administering targeted therapy or selecting appropriate candidates to participate in early-stage clinical trials from our institution. We postulated that a small gene panel such as the TsT26 panel including several genes implicated in targeted therapy and targets required for the recruitment to specific early-stage clinical trials would be suitable to fulfill our care necessity. In order to test the panel capacities, the study first aimed to demonstrate whether it could be used to determine the mutational status of three precise genes (i.e. $K R A S, N R A S$ and $B R A F$ ), all of which are associated with treatment decision-making in CRC. For that purpose, we managed an inter-laboratory validation to incorporate the assay in routine clinical practice. Between 2015 and 2017, the laboratory subsequently employed the panel in usual activity. Second, we describe 
88 successful use of the TsT26 panel in 399 patients presenting diverse tumorigenesis and evaluate

89 the utility of the panel in the clinical context.

91 Material and Methods

92 FFPE tissue collection

The TsT26 panel performance was conducted in three clinical centers: Hospital Del Mar

Medical Research Institute (Barcelona, Spain, $\mathrm{n}=16$ ), Vall d'Hebron University hospital (Barcelona, Spain, n=16) and Fundación Jiménez Díaz University hospital (Madrid, Spain, n=16). The Madrid Science Park was an additional collaborating entity. It overall included archived

97 formalin-fixed, paraffin-embedded (FFPE) tissue material from 48 patients presenting primary 98 colorectal cancer with a previously determined mutational status of $K R A S, N R A S$ and $B R A F$ genes. Samples were obtained from MARBiobank (PT17/0015/0002), VHIR-Biobank (PT17/0015/0026) and the Biobank Fundación Jiménez Díaz (PT17/0015/0006), each belonging to the Spanish National Biobanks Network. Additional FFPE samples from a variety of tumor types were used in TsT26 panel testing at the Fundación Jiménez Díaz University hospital (Madrid, Spain, n=399). Written consent was received from each donor (Data S1 and S2). All investigations followed standard operating procedures with the approval of the Fundación Jiménez Díaz University hospital Ethics and Scientific Committee (PIC 23-2012) and were conducted in accordance to the principles outlined in the Declaration of Helsinki.

Quality control (QC) 1 for tumor-cell content

FFPE tissue sections ( $4 \mu \mathrm{m}$ thick) were obtained for hematoxylin and eosin staining (Dako 
110 A pathologist (SMR-P and FR) examined the samples for tumor-cell content, scored them for

111 percentage of neoplastic nuclei and circled the tumor area. For TCC of below 30\%,

112 macrodissection was performed with a scalpel blade (Fig. S1A).

113 DNA isolation

114 Consecutive FFPE tissue sections were obtained to extract genomic DNA according to the 115 specimen type. Surgical resections were sectioned $10 \mu \mathrm{m}$ thick, biopsies 30 to $40 \mu \mathrm{m}$, and 116 endoscopies and cytologies $100 \mu \mathrm{m}$ deep. Isolation was done by using the cobas ${ }^{\circledR}$ DNA Sample 117 Preparation Kit (Roche Diagnostics, Pleasanton, CA, USA) according to the manufacturer's 118 protocol. Both concentration and purity were determined by Nanodrop spectrophotometer 119 (Thermo Fischer, Waltham, MA, USA) and Qubit 3.0 fluorometer (Thermo Fisher, Waltham, MA, 120 USA).

121 TsT26 $\Delta$ Cq DNA QC2

Extracted DNA was amplified in triplicate by quantitative PCR using the KAPA SYBR 123 FAST master mix (Life technologies, Grand Island, NY) on the Lightcycler ${ }^{\circledR} 480$ system (Roche

124 Molecular System, Pleasanton, CA, USA). The amount of DNA input was established by 125 comparing the ability of DNA to be amplified in relation to a non-FFPE reference genomic DNA. 126 A $\Delta \mathrm{Cq}$ value was calculated for each sample as follows: $\Delta \mathrm{Cq}=$ mean sample $\mathrm{Cq}$ value - mean 127 non-FFPE control $\mathrm{Cq}$ value. A mean of $\Delta \mathrm{Cq}<6$ was considered appropriate for library preparation 128 despite the instructions of the protocol, which recommended $\Delta \mathrm{Cq}<4$ (Fig. S1B).

129 TsT26 Library preparation QC3

130 NGS libraries were prepared using the TsT26 panel (Illumina, San Diego, CA, USA) (Table S1), 131 a multiplexing kit of 178 amplicons covering 82 exonic regions across 26 genes (Table 1), as 
132 indicated by the TsT26 reference guide. The obtained products were checked for their base pair

133 range using 2\% agarose gel electrophoresis along with a 50 bp ladder (Sigma-Aldrich, San Luis,

134 USA) or a 2100 bioanalyzer instrument (Agilent, Santa Clara, CA, USA) (Fig. S1C). Generated

135 libraries in the 300-330 base pair range were considered suitable for sequencing. Library

136 concentration was measured using the Qubit 3.0 fluorometer (Thermo Fisher, Waltham, MA,

137 USA) and normalized to $4 \mathrm{nM}$ in elution buffer with Tris.

138 TsT26 high-throughput sequencing

139 Libraries were then diluted to 10 or $12 \mathrm{pM}$ and to 15 or $20 \mathrm{pM}$ and pooled on a v2 300-

140 cycle or v3 600-cycle sequencing kits according to the manufacturer's protocol. Sequencing was

141 achieved for both pool A and B by loading $600 \mu 1$ of library mixes. Some runs were loaded along

142 with $1 \%$ PhiX.

143 TsT26 analysis, quality metrics and variant detection

144 The integrated analysis software (Illumina, San Diego, CA, USA) including image analysis, base 145 calling and assignation of quality scores automatically performed primary analysis. The 146 sequencing analysis viewer software (SAV, Illumina, San Diego, CA, USA) confirmed quality 147 metrics by using interop files along with run info and parameters. A Phred score of Q30 was 148 considered for each run. The MiSeq Reporter software (Illumina, San Diego, CA, USA) included 149 demultiplexing, sequence alignment and variant calling. Successful sequencing runs generated 2 150 FASTQ files, 2 BAM and BAM-BAI files for each sample pool A and pool B library pair and a 151 single genomic variant call file (VCF). Integrative Genomics Viewer software (IGV, Broad 152 Institute, CA, USA) enabled to visualize sequenced regions (Thorvaldsdóttir, Robinson \& 153 Mesirov, 2013). An exportable excel format was generated for amplicon coverage assessment. 

this criterion or presented strand bias were further assessed during interpretation. A biologist (NC or SZ or CC) evaluated variants by identifying missense, frameshift, stop gain or loss, or in-frame insertion- or deletion- affected sequences. Variant classification employed ClinVar

162 (http://www.ncbi.nlm.nih.gov/clinvar) (Harrison et al., 2016; Landrum et al., 2016), COSMIC (http://cancer.sanger.ac.uk/cosmic) (Tate et al., 2019) and cbioPortal (http://www.cbioportal.org/)

164 (Cerami et al., 2012; Gao et al., 2013) databases. Additional catalogues such as CIVIC 165 (https://civicdb.org/home) (Griffith et al., 2017), OncoKB (https://oncokb.org/) (Chakravarty et al., 2017) or the Cancer genome interpreter (https://www.cancergenomeinterpreter.org/analysis)

167 (Tamborero et al., 2018) were also accessed for variant interpretation. Pathogenic, likely pathogenic, variant of uncertain significance (VUS) and benign or likely benign variants were reported according to standard guidelines (Richards et al., 2015; Hoskinson, Dubuc \& MasonSuares, 2017). A pathologist (SMR-P and FR) provided final authentication of the reported 171 variants.

173 Pyrosequencing was determined for the $K R A S$ and $N R A S$ genes using the CE-IVD therascreen 174 KRAS, NRAS and RAS Extension pyro kits (Qiagen, Hilden, Germany), according to the 175 manufacturer's instructions. 
177 The CE-IVD cobas ${ }^{\circledR} 4800$ BRAF V600 Mutation Test was used to identify $B R A F$ c.1799T $>$ A

178 (p.V600E) mutation by real time PCR technology on the cobas z 480 Analyzer (Roche

179 Diagnostics, Pleasanton, CA, USA), in agreement with the manufacturer's protocol.

The mutational status of $B R A F$ was also determined by direct sequencing using the ABI-

Prism 3730 XL DNA analyzer (Applied Biosystems Foster City, CA, USA), as previously described (Bessa et al., 2008). Primers were designed with Primer Express software (Applied Biosystems, Foster City, CA, USA) using BRAF sequences NG-007873.3: BRAF-Fw: 5'-

Statistical analysis

We hypothesized that the expected difference of the detected variants found by the NGSpanel in comparison with the reference standard should not exceed 10\%. By using the PS program (Dupont \& Plummer, 1990), the minimal sample needed to detect this difference was set to 44 samples with a power of 0,90 and a two-sided error alpha of 0,05 . For sensitivity analysis, test variants were assigned either a true positive (TP) if detected or false negative (FN) if not detected. Sensitivity was calculated as the proportion of samples with a detected variant, $\mathrm{TP} /(\mathrm{TP}+\mathrm{FN})$. We estimated specificity as the proportion of cases without a detected variant, also considered as $\mathrm{TN} /(\mathrm{FP}+\mathrm{TN})$, that is to say variants not detected by the standard reference method that the NGSpanel identified as not detected. $\mathrm{FP}=$ false positives and $\mathrm{TN}=$ true negatives. The accuracy or extent of agreement between the outcome of the two methods was determined as

$197(\mathrm{TP}+\mathrm{TN}) /(\mathrm{TP}+\mathrm{FP}+\mathrm{FN}+\mathrm{TN})$. Confidence intervals $(\mathrm{CI})$ were calculated by the method of Clopper 198 and Pearson, as previously described (Van Stralen et al., 2009; Mattocks et al., 2010; Lih et al., 
199

200

201

202

203

204

205

206

207

208

209

210

211

212

213

214

215

216

217

218

219

220

2017). A pairwise comparison using the Mann-Whitney test was applied between the two employed chemistries. A p-value of less than 0,05 was considered significant. Statistical analysis used SPSS version 21.0 software for Windows (IBM, New York, NY, USA) and GraphPad Prism version 5.0 software (GraphPad Software, Inc., La Jolla, CA). Descriptive data were expressed as the mean and $95 \%$ CI.

Results

Inter-laboratory performance of the TsT26 panel

To assess the performance of the NGS-based panel, we compared the outcomes of the test with a reference standard to identify variants in the $K R A S, N R A S$ and $B R A F$ genes. Pyrosequencing, RT-PCR and Sanger sequencing constituted the conventional methods employed as reference standard that detected 29 variants out of the 48 selected samples, the other 19 exhibited a wild-type genotype. Performance was calculated as the whole data produced by each center, that is to say 48 samples run in triplicate or 144 outcomes taken into consideration for the agreement analysis. Sensitivity, specificity and accuracy were measured to evaluate the performance of the NGS-panel test in order to describe either detection or not detection of the variants in the mentioned genes, as indicated in Table 2. Regarding the limit of detection, the observed VAFs of the variants detected by the NGS-panel ranged from 3,23\% to $68,97 \%$. Sample $1-5$ variant c.35G $>$ C (p.G12A) was not detected and samples 3-4 and 3-11 were identified as variant detected, respectively as c.34G>A (p.G12S) and c.35G $>$ T (p.G12V) (Table S2). So, the variant calling finally identified thirty variants. Center 1 was able to detect 25 variants whereas centers 2 and 3 both distinguished 29 detected variants (Fig. 1A).

High-throughput sequencing quality metrics of the panel performance 
Nine runs employing v2 300-cycle sequencing chemistry were carried out during the

222

223

224

225

226

227

228

229

230

231

232

233

validation process. Quality metrics including cluster density and cluster passing filter were found to be slightly increased in comparison to the manufacturer's guidance as depicted in Fig. 1B. Every detected variant encountered by NGS testing presented a read depth of higher than 1000x and a variant allele frequency (VAF) greater than 3\% (Figs. 1C and 1D).

\section{Patient characteristics and clinical practicability of the TsT26 panel}

A set of 399 patients was included in this study. Sex and age data were available for 386 and 365 patients, respectively. Regarding tumor types, the most common consisted of gastrointestinal (GI), hematologic, lung, gynecological, and breast samples, whereas melanoma, head and neck, genitourinary, central nervous system (CNS), and other histological cancer types were limited in number (Table S3). Overall, the sample set consisted of biopsy specimens, surgical resections, endoscopies and cytologies (Table 3). From the entire data set, 40\% was from external origin.

Two-thirds of all samples were successful in sequencing testing, while one-third failed due to unsuccessful quality-control filtering (Fig. 2A and 2B). Quality controls included initial TCC management, followed by assessment of DNA quality and final quantitation of library preparation. Failure to meet any of these quality controls lead to sequencing failure (Fig. 2C).

DNA quality assessment for high-throughput sequencing by quantitative PCR

Most samples presenting a $\Delta \mathrm{Cq}<4$ resulted in a successful NGS sequencing. Five samples were sequenced despite of showing $\Delta \mathrm{Cq}>6$ upon explicit clinical request. Several samples exhibiting a $\Delta \mathrm{Cq}$ value between 4 and 6 were able to generate valuable libraries. Consequently, we extended the cut-off value of the $\Delta \mathrm{Cq}$ to 6 . Thirty-seven samples did not undergo DNA quality 
243 assessment, 5\% of them resulting in failed NGS, 3\% in detected variants and 1\% in not detected

244 variant (Table 4). Samples that failed sequencing were to the most extent biopsy specimens $(26 \%)$.

245 Almost half of them had a poor concentration (13\%) and were from external origin (13\%), as well

246 as exhibited either a low TCC or inadequate representative tumor material $(8 \%)$.

247 Variant detection and high-throughput sequencing quality metrics during TsT26 panel

248 implementation

Detected variants were identified in 74\% (194 samples) of the successfully sequenced samples, whereas in 26\% (69 samples) variants were either not detected or a wild type genotype was found (Table S4). The highest number of detected variants was observed in the TP53 (28\%), $K R A S(16 \%), A P C(10 \%)$ and PIK3CA (8\%) genes. In contrast, a lower amount of detected variants was encountered in MET (5\%), BRAF (4\%), SMAD4 (3\%), as well as in KIT, PTEN, NRAS, CTNNB1, FBXW7, CDH1, HER2, (2\% each) and GNAS, MAP2K1, STK11, EGFR, PDGFRA, MSH6, FGFR2, GNAQ, SRC (1\% each). No variants were detected in the AKT1, ALK and FOXL2 genes (Fig. 3A). and 20 using v3 600-cycle sequencing chemistries. Although certain runs experienced underclustering, the mean cluster density was found within the optimal range recommended by the manufacturer between 1000 and 1400 clusters per $\mathrm{mm}^{2}\left(\mathrm{~K} / \mathrm{mm}^{2}\right)$. Accordingly, these runs showed a high percentage value of cluster passing filter that lead to an elevated mean of this parameter (Fig. 3B). We found statistically significant differences between the cluster density and cluster 263 passing filter of the employed v2 and v3 chemistries, $887(95 \% \mathrm{CI}=735-1039)$ and 1230 264 $(95 \% \mathrm{CI}=1074-1386) \mathrm{k} / \mathrm{mm} 2, \mathrm{p}=0,0024$; and $94 \%(95 \% \mathrm{CI}=93-96)$ compared to $91 \%(95 \% \mathrm{CI}=88$ 93), $\mathrm{p}=0,0093$, together in accordance with the manufacturer's guidelines. A read depth of greater 
266 than 1000x was observed for each gene, except in two skin melanomas presenting a reduced depth

267 value that subsequently required further corroboration by additional molecular testing.

268 Additionally, every detected variant demonstrated a VAF greater than $3 \%$. The MET gene showed

269 the highest VAF mean in comparison to the other studied genes (Figs. 3C and 3D).

Coverage by amplicon was calculated by obtaining the mean of each amplicon covering each exonic region. The mean coverage of $A K T 1$ exon 2 and STK11 exon 6 did not satisfy the minimum coverage of $1000 x$ required by the panel. In addition, EGFR ex21, STK11 exons 1, 4, 8 and TP53 exon 11 presented the same condition although this was compensated by cumulatively counting the coverage of the second pool (Fig. S2).

$277(22 \%), A P C(16 \%)$ and PIK3CA (8\%) genes. Furthermore, detected variants were identified in the same genes in gynecological tumors, whereas in lung there were more recurrently perceived variants in only TP53 (33\%) and KRAS (21\%) genes. In contrast, detected variants in hematologic malignancies were merely seen in the $K R A S$ gene (Fig. 4). In melanoma, $46 \%$ of the detected variants were found in $B R A F$ and $15 \%$ in $N R A S$ genes. In breast, the TP53 and PIK3CA genes presented a highest number of affected variants in comparison to other genes. Whereas genitourinary, head and neck, and SNC tumor types exhibited at least one detected variant per gene except in TP53, PIK3CA and MET (Fig. S3). 
$288(9 \%)$ and frameshift $(7 \%)$ affected sequences. Minor alterations corresponded to in-frame 289 deletions (2\%), splice region variants (1\%), in-frame insertions (1\%) and start lost (1\%). Most 290 detected variants were reported as pathogenic (78\%) or likely pathogenic (1\%), whereas $19 \%$ of 291 variants were classified as VUS and 2\% as benign or likely benign. The variants more frequently 292 observed were: KRAS c.35G>A (p.G12D) and c.35G>T (p.G12V), but also MET c.504G>T 293 (p.E168D) in GI tumors; TP53 c.742C>T (p.R248W) in hematologic malignancies; KRAS 294 c.34G $>$ T (p.G12C) and c.35G>T (p.G12V) in lung; PIK3CA c.3140A >G (p.H1047R) and c.3140A $>$ T (p.H1047L) in breast and $B R A F$ c.1799T $>$ A (p.V600E) in both melanoma and head 296 and neck cancers (Table S5).

Gene mutation frequencies by histological tumor types

We further compared mutation frequencies of the genes presenting detected variants against those encountered in the TGCA database for each histologic tumor type. Similarity was 300 observed when relating mutations frequencies of genes contained in the TsT26 panel to those from the TCGA set for most of the tumors included in the study. For instance, $K R A S, T P 53, A P C$, PIK3CA, SMAD4, FBXW7 and BRAF genes presented higher mutation frequencies in CRC. The prevalence of additional genes in other tumor types can be seen in Figs. S4 and S5. Hepatocarcinoma, cervical and mesothelioma tumor types did not present a sufficient number of cases to perform comparisons.

After reviewing the medical records of the 194 patients presenting detected variants in a 308 range of genes after applying the TsT26 panel, we were able to associate a subsequent clinical 309 action to a reported detected molecular alteration (Table S6). Arising from the 372 detected 
310 variants found, $37 \%$ were considered clinically relevant and a treatment decision was attempted in

$31113 \%$. Only $14 \%$ of patients received targeted therapy based on the variant detected by the TsT26

312 panel (Table S7).

313 Discussion

314 In this study, we conducted an inter-laboratory validation of the TsT26 panel based on the

315 detection of alterations in three genes of potential therapy interest. We obtained robust data

316 regarding the detection of relevant and likely targetable variants across multiple tumors from 399

317 patients, despite a large number of samples that failed strict quality assessments. Reporting of

318 detected variants was supported by adequate sequencing metrics and subsequent clinical decision-

319 making when indicated.

320 Concerning the discordant results obtained during the validation process, any of the

321 involved centers was able to authenticate the original mutation c.35G $>\mathrm{C}$ (p.G12A) reported by

322 center 1 in $K R A S$. After performing re-test in both previous sections and a second isolation of

323 DNA, the sample still resulted mutated, leading to tumor heterogeneity as a concluding

324 interpretation of the case. On the other hand, the sequencing analysis found the mutational status

325 of samples 3-4 and 3-11 as mutated for KRAS. The two variants exhibited a low VAF (3,23\% for

326 c.34G $>$ A (p.G12S) in center $2 ; 7,71 \%$ and $8,37 \%$ for c.35G $>$ T (p.G12V) in centers 2 and 3 ,

327 respectively) that could not be originally detected by the gold standard method, pyrosequencing.

328 Finally, center 3 corroborated the two variants identified by the TsT26 panel using another

329 platform with a more accurate sensitivity employing qPCR technology. Unfortunately, center 1

330 was unable to recognize any of the two variants during the high-throughput sequencing analysis.

331 Overall, $29+29+29=87$ variants represented the $100 \%$ of variants detected by the reference

332 standard whereas the NGS-panel was only able to identify $25+29+29=83$ variants. This 
333 represented a difference of $5 \%$ with respect to the total number of variants recognized by the

334 reference standard. Therefore, not exceeding the expected difference to be found in the comparison

335 evaluation. Only center 1 failed in the performance assessment because it only detected 25 variants

336 out of the 29 detected variants to be distinguished. We should also acknowledge certain limitation

337 in our evaluation process as we did not calculate reproducibility after establishing test sensitivity,

338 specificity and accuracy with respect to the reference standard.

The TsT26 panel incorporated rigorous pre-analytical requirements to obtain a favorable sequencing outcome. Samples were primarily evaluated for their TCC. Although a minimum of $30 \%$ of TCC was established as the cut-off value, a large number of samples with a lower TCC were selected to begin the panel testing, in part, because the standard reference of the laboratory was established as a $10 \%$ value as the minimum TCC, however most of these samples underwent tissue macrodissection. Secondly, DNA quality was assessed by qRT-PCR. Indeed, this estimation is considered a better indicator of amplifiable material than other common methods such as fluorometric and spectrophotometric evaluations, the latter usually overestimating the amount of double stranded DNA (Deans et al., 2017). A final quality control measured library adequacy for sequencing. Despite showing good DNA quality as demonstrated by a favorable qRT-PCR assessment, several samples failed the library-generation procedure as they did not meet the appropriate right base pair size. Therefore, such a strict quality control undertaken before initiating the sequencing may justify the elevated inadequacy rate of samples that failed the TsT26 testing. with previous published NGS results. In 52 colorectal tumors, KRAS, TP53 and $A P C$ were the genes affected with most detected variants using the same panel TsT26 (Giardina et al., 2018). The 
356 adenocarcinomas, TP53, KRAS and PIK3CA showed the highest percentages of detected variants

357 per gene using the ion torrent AmpliSeq Cancer Hotspot v2 assay (Tsongalis et al., 2014).

358 Similarly, TP53, KRAS and $A P C$ presented more somatic alterations in the set of lung samples,

359 whereas $P I K 3 C A$ was represented in a much lower proportion. Others confirmed the elevated

360 quantity of mutations in the $K R A S$ gene despite the use of a limited sample size (Patel et al., 2017)

361 or a much larger data set (Legras et al., 2018). An implementation study employing a customized

362 Ampliseq NGS panel including 35 genes reported $B R A F, T E R T$ and $N R A S$ as the most prevalent

363 mutated genes in a set of 100 primary melanoma samples (De Unamuno Bustos et al., 2017). BRAF

364 and $N R A S$ were also the more frequently mutated genes in melanoma samples as described by

365 others (Fisher et al., 2016; Giardina et al., 2018), except the TERT gene which was not included in

366 the NGS panel.

Numerous studies have characterized a prior validation to implement an NGS-based panel commonly employed in the assessment of targeted therapies for solid tumors (Tsongalis et al., 2014; Csernak et al., 2017; Kou et al., 2017; Luthra et al., 2017; Lee et al., 2018; Maxwell et al., 2018; Sussman et al., 2018; Williams et al., 2018). Similarly, other authors corroborated its use on pediatric hematologic malignancies (Kluk et al., 2016) or myeloid neoplasms (Maes et al., 2017). In contrast, another investigation has directly focused on a concrete cancer type such as in nonsmall cell lung cancer (NSCLC) (Legras et al., 2018). Although several studies validated NGSbased panels on both solid tumors and hematologic malignancies (Cottrell et al., 2014; Garcia et al., 2017), few reports have aimed to demonstrate that the TsT26 panel is a validated method to implement in the clinical practice in a considerable number of varied tumor tissues (Fisher et al., 2016; Giardina et al., 2018). In addition, this panel has also been used to validate another molecular testing platform in 90 NSCLC tumor samples (Quinn et al., 2015). A greater number of validation 
379 studies in high-throughput sequencing with its consequent application in the real world would

380 allow a better knowledge about the identification of variants with a clinically relevant significance,

381 thus improving the integration of this technology in the clinical setting. Although the TsT26 panel

382 was indicated for the analysis of solid tumors, we also underwent extra solid tumors types and

383 hematologic malignancies samples across the panel. This is certainly not the most appropriate

384 panel to test hematologic malignancies. Particular customized panels are exclusively designed for

385 that purpose such as the personalized panel including 48 genes in T-cell lymphomas (Manso et al.,

386 2018). Despite that, detected variants were found in the TP53 gene allowing a concrete clinical

387 decision-making and prognosis of several subgroups of lymphomas (Xu-Monette et al., 2012).

388 Other limitations may be recognized in the present study. Even though the validation

389 analysis exhibited good concordance regarding the $K R A S, N R A S$ and $B R A F$ genes, supplementary

390 verification considering the rest of the targeted genes would probably demand additional

391 authentication. Another constraint concerns the kind of genetic aberration that the panel is able to

392 recognize. Essentially, the panel merely detects either single or multiple nucleotide variants in a

393 restricted number of genes and cannot identify gene fusions. Moreover, concrete exonic regions

394 of the genes $A K T 1, S T K 11, E G F R$ and TP53 were not adequately covered, thus slightly reducing

395 the sum of gene regions analyzed by the panel.

396 Despite incorporating a limited number of genes, most of the genes included were tightly

397 linked to potential FDA-approved clinical actionability, such as $B R A F$ mutations c.1799T $>$ A

398 (p.V600E) in melanoma regarding dabrafenib, trametinib or vemurafenib treatments, and EGFR

399 tyrosine-kinase domain mutations in NSCLC for afatinib, erlotinib, gefitinib and osimertinib

400 therapies (Hovelson et al., 2015; Paasinen-Sohns et al., 2017). Likewise, PIK3CA mutations in

401 patients with hormone receptor positive and ERBB2-negative advanced breast cancer who 
402 previously received endocrine therapy for alpelisib-fulvestrant (André et al., 2019). As well, KIT

403 mutations in GIST for regorafenib, sunitinib and imatinib drugs (Demetri et al., 2013). Novel

404 NGS-targeted panels may include a much larger number of genes to be tested as demonstrated by 405 a panel targeting 170 genes that proved to bring relevant clinical information on diffuse gliomas 406 by improving both diagnosis and prognosis (Na et al., 2019). Other panels can detect further 407 alterations such as fusions and copy number variations in combination with point mutations in an 408 elevated number of genes (Luthra et al., 2017). In fact, the eligibility of the NGS-based panel 409 remains of vital importance according to the kind of alterations that need to be targeted.

410 Conclusions

411 Inter-laboratory validation permitted effective NGS-based panel testing in 399 samples of diverse 412 tumorigenesis. Two-thirds of the samples were able to be sequenced and 372 variants were 413 identified. Reporting of clinically relevant variants allowed subsequent clinical decision-making 414 and targeted treatment administration. However, the findings of the study are limited by high 415 sample inadequacy rate (one-third), mainly explained by the strict quality assessments 416 recommended by the manufacturer, thus generating some uncertainty regarding its continuity in 417 the clinical setting.

418 Acknowledgments

419 We particularly would like to thank the participating patients for their collaboration in the present 420 study and the Biobank Fundación Jiménez Díaz (PT17/0015/0006). We are also grateful to 421 pathology residents Ana Martínez López, Emilce Aguirre, Alvaro Pezella Risueño and María 422 Trujillo Coronado for their assistance in variant classification during their rotation in the the 423 Fundación Jiménez Díaz university hospital molecular diagnostics laboratory. 
426

427

428

429

430

431

432

433

434

435

436

437

438

439

440

441

442

443

444

445

446

André F, Ciruelos E, Rubovszky G, Campone M, Loibl S, Rugo HS, Iwata H, Conte P, Mayer IA, Kaufman B, Yamashita T, Lu Y-S, Inoue K, Takahashi M, Pápai Z, Longin A-S, Mills D, Wilke C, Hirawat S, Juric D. 2019. Alpelisib for PIK3CA -Mutated, Hormone Receptor-Positive Advanced Breast Cancer . New England Journal of Medicine 380:19291940. DOI: $10.1056 /$ nejmoa1813904.

Bessa X, Ballesté B, Andreu M, Castells A, Bellosillo B, Balaguer F, Castellví-bel S, Paya A, Jover R, Alenda C, Titó L, Martinez-Villacampa M, Vilella A, Xicola RM, Pons E, Llor X. 2008. A Prospective, Multicenter, Population-Based Study of BRAF Mutational Analysis for Lynch Syndrome Screening. Clinical Gastroenterology and Hepatology 6:206-214. DOI: $10.1016 /$ j.cgh.2007.10.011.

Cerami E, Gao J, Dogrusoz U, Gross BE, Sumer SO, Aksoy BA, Jacobsen A, Byrne CJ, Heuer ML, Larsson E, Antipin Y, Reva B, Goldberg AP, Sander C, Schultz N. 2012. The cBio Cancer Genomics Portal: An Open Platform for Exploring Multidimensional Cancer Genomics Data. Cancer Discovery 2:401-404. DOI: 10.1158/2159-8290.cd-12-0095.

Chakravarty D, Gao J, Phillips S, Kundra R, Zhang H, Wang J, Rudolph J, Yaeger R, Soumerai T, Nissan M, Chang M, Chandarlapaty S, Traina T, Paik P, Ho A, Hantash F, Gupe A, Baxi S, Callahan M, Snyder A, Chi P, Danila D, Gounder M, Harding J, Hellman M, Iyer G, Janjigian Y, Kaley T, Levine D, Lowery M, Omuro A, Postow M, Rathkopf D, Shoushtari A, Shukla N, Voss M, Paraiso E, Zehir A, Berger M, Taylor B, Saltz L, Riely G, Ladanyi M, Hyman D, Baselga J, Sabbatini P, Solit D, Schultz N. 2017. OncoKB: A Precision Oncology Knowledge Base. JCO Precision Oncology 1:1-16. DOI: 10.1200/PO.17.00011. 
447 Cottrell CE, Al-Kateb H, Bredemeyer AJ, Duncavage EJ, Spencer DH, Abel HJ, Lockwood CM, 448 Hagemann IS, O’Guin SM, Burcea LC, Sawyer CS, Oschwald DM, Stratman JL, Sher DA, 449 Johnson MR, Brown JT, Cliften PF, George B, McIntosh LD, Shrivastava S, Nguyen TT, 450 Payton JE, Watson MA, Crosby SD, Head RD, Mitra RD, Nagarajan R, Kulkarni S, Seibert

451

452

453

454

455

456

457

458

459

460

461

462

463

464

465

466

467

468

469

Csernak E, Molnar J, Tusnady GE, Toth E. 2017. Application of Targeted Next-generation Sequencing, TruSeq Custom Amplicon Assay for Molecular Pathology Diagnostics on Formalin-fixed and Paraffin-embedded Samples. Applied Immunohistochemistry and Molecular Morphology 25:460-466. DOI: 10.1097/PAI.0000000000000325.

Deans ZC, Costa JL, Cree I, Dequeker E, Edsjö A, Henderson S, Hummel M, Ligtenberg MJ, Loddo M, Machado JC, Marchetti A, Marquis K, Mason J, Normanno N, Rouleau E, Schuuring E, Snelson KM, Thunnissen E, Tops B, Williams G, van Krieken H, Hall JA. 2017. Integration of next-generation sequencing in clinical diagnostic molecular pathology laboratories for analysis of solid tumours; an expert opinion on behalf of IQN Path ASBL. Virchows Archiv 470:5-20. DOI: 10.1007/s00428-016-2025-7.

Demetri G, Reichardt P, Kang Y, Blay JY, Rutkowski P, Gelderblom H, Hohenberger P, Leahy M, von Mehren M, Joensuu H, Badalamenti G, Blackstein M, Le Cesne A, Schöffski P, Maki RG, Bauer S, Nguyen BB, Xu J, Nishida T, Chung J, Kappeler C, Kuss I, Laurent D, Casali PG. 2013. Efficacy and safety of regorafenib for advanced gastrointestinal stromal tumours after failure of imatinib and sunitinib: an international, multicentre, randomised, placebo-controlled, phase 3 trial (GRID). The Lancet 381:295-302. DOI: 10.1016/s0140- 
471

472

473

474

475

476

477

478

479

480

481

482

483

484

485

486

487

488

489

490

491

Dong L, Wang W, Li A, Kansal R, Chen Y, Chen H, Li X. 2015. Clinical next generation sequencing for precision medicine in cancer. Current Genomics 16:253-263. DOI: $10.2174 / 1389202915666150511205313$.

Dupont W, Plummer W. 1990. Power and Sample Size Calculations: A Review and Computer Program. Controlled Clinical Trials 11:116-128. DOI: 10.1016/0197-2456(90)90005-m.

Fisher KE, Zhang L, Wang J, Smith GH, Newman S, Schneider TM, Pillai RN, Kudchadkar RR, Owonikoko TK, Ramalingam SS, Lawson DH, Delman KA, El-Rayes BF, Wilson MM, Sullivan HC, Morrison AS, Balci S, Adsay NV, Gal AA, Sica GL, Saxe DF, Mann KP, Hill CE, Khuri FR, Rossi MR. 2016. Clinical Validation and Implementation of a Targeted Next-Generation Sequencing Assay to Detect Somatic Variants in Non-Small Cell Lung, Melanoma, and Gastrointestinal Malignancies. Journal of Molecular Diagnostics 18:299315. DOI: 10.1016/j.jmoldx.2015.11.006.

Friedman AA, Letai A, Fisher DE, Flaherty KT. 2015. Precision medicine for cancer with nextgeneration functional diagnostics. Nature Reviews Cancer 15:747-756. DOI: $10.1038 / \operatorname{nrc} 4015$.

Gao J, Aksoy BA, Dogrusoz U, Dresdner G, Gross B, Sumer SO, Sun Y, Jacobsen A, Sinha R, Larsson E, Cerami E, Sander C, Schultz N. 2013. Integrative analysis of complex cancer genomics and clinical profiles using the cBioPortal. Science Signaling 6:1-19. DOI: 10.1126/scisignal.2004088.

Garcia EP, Minkovsky A, Jia Y, Ducar MD, Shivdasani P, Gong X, Ligon AH, Sholl LM, Kuo FC, MacConaill LE, Lindeman NI, Dong F. 2017. Validation of oncopanel a targeted next- 
492

493

494

495

496

497

498

499

500

501

502

503

504

505

506

507

508

509

510

511

512

513

generation sequencing assay for the detection of somatic variants in cancer. Archives of Pathology and Laboratory Medicine 141:751-758. DOI: 10.5858/arpa.2016-0527-OA.

Giardina T, Robinson C, Grieu-Iacopetta F, Millward M, Iacopetta B, Spagnolo D, Amanuel B. 2018. Implementation of next generation sequencing technology for somatic mutation detection in routine laboratory practice. Pathology 50:389-401. DOI: 10.1016/j.pathol.2018.01.005.

Griffith M, Spies NC, Krysiak K, McMichael JF, Coffman AC, Danos AM, Ainscough BJ, Ramirez CA, Rieke DT, Kujan L, Barnell EK, Wagner AH, Skidmore ZL, Wollam A, Liu CJ, Jones MR, Bilski RL, Lesurf R, Feng Y-Y, Shah NM, Bonakdar M, Trani L, Matlock M, Ramu A, Campbell KM, Spies GC, Graubert AP, Gangavarapu K, Eldred JM, Larson DE, Walker JR, Good BM, Wu C, Su AI, Dienstmann R, Margolin AA, Tamborero D, Lopez-Bigas N, Jones SJM, Bose R, Spencer DH, Wartman LD, Wilson RK, Mardis ER, Griffith OL. 2017. CIViC is a community knowledgebase for expert crowdsourcing the clinical interpretation of variants in cancer. Nature Genetics 49:170-174. DOI: 10.1038/ng.3774.

Harrison SM, Riggs ER, Maglott DR, Lee JM, Azzariti DR, Niehaus A, Ramos EM, Martin CL, Landrum MJ, Rehm HL. 2016. Using ClinVar as a resource to support variant interpretation. Current Protocols in Human Genetics 89:8.16.1-8.16.23. DOI: 10.1002/0471142905.hg0816s89.

Hoskinson DC, Dubuc AM, Mason-Suares H. 2017. The current state of clinical interpretation of sequence variants. Current Opinion in Genetics and Development 42:33-39. DOI: 10.1016/j.gde.2017.01.001. 
514 Hovelson DH, McDaniel AS, Cani AK, Johnson B, Rhodes K, Williams PD, Bandla S, Bien G,

515 Choppa P, Hyland F, Gottimukkala R, Liu G, Manivannan M, Schageman J, Ballesteros-

516 Villagrana E, Grasso CS, Quist MJ, Yadati V, Amin A, Siddiqui J, Betz BL, Knudsen KE,

517 Cooney KA, Feng FY, Roh MH, Nelson PS, Liu CJ, Beer DG, Wyngaard P, Chinnaiyan

518 AM, Sadis S, Rhodes DR, Tomlins SA. 2015. Development and Validation of a Scalable

519 Next-Generation Sequencing System for Assessing Relevant Somatic Variants in Solid

520 Tumors. Neoplasia 17:385-399. DOI: 10.1016/j.neo.2015.03.004.

521 Hyman DM, Taylor BS, Baselga J. 2017. Implementing Genome-Driven Oncology. Cell

522

168:584-599. DOI: 10.1016/j.cell.2016.12.015.

523

524

525

526

527

528

529

530

531

532

533

534

535

Jennings LJ, Arcila ME, Corless C, Kamel-Reid S, Lubin IM, Pfeifer J, Temple-Smolkin RL, Voelkerding K V, Nikiforova MN. 2017. Guidelines for Validation of Next-Generation Sequencing-Based Oncology Panels: A Joint Consensus Recommendation of the Association for Molecular Pathology and College of American Pathologists. Journal of Molecular Diagnostics 19:341-365. DOI: 10.1016/j.jmoldx.2017.01.011.

Kluk MJ, Lindsley RC, Aster JC, Lindeman NI, Szeto D, Hall D, Kuo FC. 2016. Validation and Implementation of a Custom Next-Generation Sequencing Clinical Assay for Hematologic Malignancies. Journal of Molecular Diagnostics 18:507-515. DOI: 10.1016/j.jmoldx.2016.02.003.

Kou T, Kanai M, Yamamoto Y, Kamada M, Nakatsui M, Sakuma T, Mochizuki H, Hiroshima A, Sugiyama A, Nakamura E, Miyake H, Minamiguchi S, Takaori K, Matsumoto S, Haga H, Seno H, Kosugi S, Okuno Y, Muto M. 2017. Clinical sequencing using a next-generation sequencing-based multiplex gene assay in patients with advanced solid tumors. Cancer 
Science 108:1440-1446. DOI: 10.1111/cas.13265.

537 Landrum MJ, Lee JM, Benson M, Brown G, Chao C, Chitipiralla S, Gu B, Hart J, Hoffman D,

538 Hoover J, Jang W, Katz K, Ovetsky M, Riley G, Sethi A, Tully R, Villamarin-Salomon R, 539 Rubinstein W, Maglott DR. 2016. ClinVar: Public archive of interpretations of clinically $540 \quad$ relevant variants. Nucleic Acids Research 44:D862-D868. DOI: 10.1093/nar/gkv1222.

541 Lee A, Lee SH, Jung CK, Park G, Lee KY, Choi HJ, Min KO, Kim TJ, Lee EJ, Lee YS. 2018.

542 Use of the Ion AmpliSeq Cancer Hotspot Panel in clinical molecular pathology laboratories 543 for analysis of solid tumours: With emphasis on validation with relevant single molecular 544 pathology tests and the Oncomine Focus Assay. Pathology Research and Practice 214:713545 719. DOI: 10.1016/j.prp.2018.03.009.

546

547

548

549

550

551

552

553

554

555

556

557

Legras A, Barritault M, Tallet A, Fabre E, Guyard A, Rance B, Digan W, Pecuchet N, GirouxLeprieur E, Julie C, Jouveshomme S, Duchatelle V, Giraudet V, Gibault L, Cazier A, Pastre J, Le Pimpec-Barthes F, Laurent-Puig P, Blons H. 2018. Validity of Targeted NextGeneration Sequencing in Routine Care for Identifying Clinically Relevant Molecular Profiles in Non-Small-Cell Lung Cancer: Results of a 2-Year Experience on 1343 Samples. Journal of Molecular Diagnostics 20:550-564. DOI: 10.1016/j.jmoldx.2018.04.002.

Lih CJ, Harrington RD, Sims DJ, Harper KN, Bouk CH, Datta V, Yau J, Singh RR, Routbort MJ, Luthra R, Patel KP, Mantha GS, Krishnamurthy S, Ronski K, Walther Z, Finberg KE, Canosa S, Robinson H, Raymond A, Le LP, McShane LM, Polley EC, Conley BA, Doroshow JH, Iafrate AJ, Sklar JL, Hamilton SR, Williams PM. 2017. Analytical Validation of the Next-Generation Sequencing Assay for a Nationwide Signal-Finding Clinical Trial: Molecular Analysis for Therapy Choice Clinical Trial. Journal of Molecular 
Diagnostics 19:313-327. DOI: 10.1016/j.jmoldx.2016.10.007.

559

560

561

562

563

564

565

566

567

568

569

570

571

572

573

574

575

576

577

578

579

Luthra R, Chen H, Roy-Chowdhuri S, Singh RR. 2015. Next-generation sequencing in clinical molecular diagnostics of cancer: Advantages and challenges. Cancers 7:2023-2036. DOI: 10.3390/cancers 7040874 .

Luthra R, Patel KP, Routbort MJ, Broaddus RR, Yau J, Simien C, Chen W, Hatfield DZ, Medeiros LJ, Singh RR. 2017. A Targeted High-Throughput Next-Generation Sequencing Panel for Clinical Screening of Mutations, Gene Amplifications, and Fusions in Solid Tumors. Journal of Molecular Diagnostics 19:255-264. DOI: 10.1016/j.jmoldx.2016.09.011.

Maes B, Willemse J, Broekmans A, Smets R, Cruys B, Put N, Madoe V, Janssen M, Soepenberg O, Bries G, Vrelust I, Achten R, Van Pelt K, Buvé K, Theunissen K, Peeters V, Froyen G. 2017. Targeted next-generation sequencing using a multigene panel in myeloid neoplasms: Implementation in clinical diagnostics. International Journal of Laboratory Hematology 39:604-612. DOI: 10.1111/ijlh.12709.

Manso R, González-Rincón J, Rodríguez-Justo M, Gómez S, Sánchez-Beato M, Piris MA, Rodríguez-Pinilla SM. 2018. Overlap at the molecular and immunohistochemical levels between angioimmunoblastic T-cell lymphoma and a subgroup of peripheral T-cell lymphomas without specific morphological features. Oncotarget 9:16124-16133. DOI: 10.18632/oncotarget.24592.

Matthijs G, Souche E, Alders M, Corveleyn A, Eck S, Feenstra I, Race V, Sistermans E, Sturm M, Weiss M, Yntema H, Bakker E, Scheffer H, Bauer P. 2016. Guidelines for diagnostic next-generation sequencing. European Journal of Human Genetics 24:2-5. DOI: 
581

582

583

584

585

586

587

588

589

590

591

592

593

594

595

596

597

598

599

600

601

Mattocks CJ, Morris MA, Matthijs G, Swinnen E, Corveleyn A, Dequeker E, Müller CR, Pratt V, Wallace A. 2010. A standardized framework for the validation and verification of clinical molecular genetic tests. European Journal of Human Genetics 18:1276-1288. DOI: 10.1038/ejhg.2010.101.

Maxwell P, Hynes SO, Fuchs M, Craig S, McGready C, McLean F, McQuaid S, James J, SaltoTellez M. 2018. Practical guide for the comparison of two next-generation sequencing systems for solid tumour analysis in a universal healthcare system. Journal of Clinical Pathology 0:1-7. DOI: 10.1136/jclinpath-2017-204917.

McCourt CM, McArt DG, Mills K, Catherwood MA, Maxwell P, Waugh DJ, Hamilton P, O’Sullivan JM, Salto-Tellez M. 2013. Validation of Next Generation Sequencing Technologies in Comparison to Current Diagnostic Gold Standards for BRAF, EGFR and KRAS Mutational Analysis. PLoS ONE 8:e69604. DOI: 10.1371/journal.pone.0069604.

Morganti S, D’Amico P, Ferraro E, Trapani D, Tarantino P, Duso BA, Viale G, Curigliano G. 2019. Complexity of genome sequencing and reporting: Next generation sequencing (NGS) technologies and implementation of precision medicine in real life. Critical Reviews in Oncology/Hematology 133:171-182. DOI: 10.1016/j.critrevonc.2018.11.008.

Na K, Kim HS, Shim HS, Chang JH, Kang SG, Kim SH. 2019. Targeted next-generation sequencing panel (TruSight Tumor 170) in diffuse glioma: a single institutional experience of 135 cases. Journal of Neuro-Oncology 142:445-454. DOI: 10.1007/s11060-019-03114- 
602 603 604 605 606 607 608 609 generation sequencing-based gene panel tests for the management of solid tumors. Cancer Science 110:6-15. DOI: 10.1111/cas.13837.

Paasinen-Sohns A, Koelzer VH, Frank A, Schafroth J, Gisler A, Sachs M, Graber A, Rothschild SI, Wicki A, Cathomas G, Mertz KD. 2017. Single-Center Experience with a Targeted Next Generation Sequencing Assay for Assessment of Relevant Somatic Alterations in Solid Tumors. Neoplasia 19:196-206. DOI: 10.1016/j.neo.2017.01.003.

Patel SB, Kadi W, Walts AE, Marchevsky AM, Pao A, Aguiluz A, Mudalige T, Liu Z, Deng N, Lopategui J. 2017. Next-Generation Sequencing: A Novel Approach to Distinguish Multifocal Primary Lung Adenocarcinomas from Intrapulmonary Metastases. Journal of Molecular Diagnostics 19:870-880. DOI: 10.1016/j.jmoldx.2017.07.006.

Quinn AM, Hickson N, Adaway M, Priest L, Jaeger E, Udar N, Keeling C, Kamieniorz M, Dive C, Wallace A, Byers RJ, Newman WG, Nonaka D, Blackhall FH. 2015. Diagnostic mutation profiling and validation of non-small-cell lung cancer small biopsy samples using a high throughput platform. Journal of Thoracic Oncology 10:784-792. DOI: 10.1097/JTO.0000000000000473.

Richards S, Aziz N, Bale S, Bick D, Das S, Gastier-Foster J, Grody WW, Hegde M, Lyon E, Spector E, Voelkerding K, Rehm HL. 2015. Standards and guidelines for the interpretation of sequence variants: A joint consensus recommendation of the American College of Medical Genetics and Genomics and the Association for Molecular Pathology. Genetics in Medicine 17:405-424. DOI: 10.1038/gim.2015.30.

Sepulveda AR, Hamilton SR, Allegra CJ, Grody W, Cushman-Vokoun AM, Funkhouser WK, Kopetz SE, Lieu C, Lindor NM, Minsky BD, Monzon FA, Sargent DJ, Singh VM, Willis J, 
624 Clark J, Colasacco C, Rumble RB, Temple-Smolkin R, Ventura CB, Nowak JA. 2017.

625 Molecular Biomarkers for the Evaluation of Colorectal Cancer: Guideline From the

626 American Society for Clinical Pathology, College of American Pathologists, Association for

627 Molecular Pathology, and the American Society of Clinical Oncology. Journal of Clinical

628 Oncology 35:1453-1486. DOI: 10.1200/JCO.2016.71.9807.

629 Van Stralen KJ, Stel VS, Reitsma JB, Dekker FW, Zoccali C, Jager KJ. 2009. Diagnostic

630 methods I: Sensitivity, specificity, and other measures of accuracy. Kidney International

$631 \quad$ 75:1257-1263. DOI: 10.1038/ki.2009.92.

632 Surrey LF, Luo M, Chang F, Li MM. 2016. The Genomic Era of Clinical Oncology: Integrated

633 Genomic Analysis for Precision Cancer Care. Cytogenetic and Genome Research 150:162-

634 175. DOI: $10.1159 / 000454655$.

635 Sussman RT, Shaffer S, Azzato EM, Desloover D, Farooqi MS, Meyer A, Lieberman DB,

636 Bigdeli A, Paolillo C, Ganapathy K, Sukhadia S, Rosenbaum JN, Daber RD, Morrissette

637 JJD. 2018. Validation of a next-generation sequencing oncology panel optimized for low

638 input DNA. Cancer Genetics 228-229:55-63. DOI: 10.1016/j.cancergen.2018.08.004.

639 Tamborero D, Rubio-Perez C, Deu-Pons J, Schroeder MP, Vivancos A, Rovira A, Tusquets I,

640 Albanell J, Rodon J, Tabernero J, de Torres C, Dienstmann R, Gonzalez-Perez A, Lopez-

641 Bigas N. 2018. Cancer Genome Interpreter annotates the biological and clinical relevance of

642 tumor alterations. Genome Medicine 10:1-8. DOI: 10.1186/s13073-018-0531-8.

643 Tan O, Shrestha R, Cunich M, Schofield DJ. 2018. Application of next-generation sequencing to

644 improve cancer management: A review of the clinical effectiveness and cost-effectiveness.

645 Clinical Genetics 93:533-544. DOI: 10.1111/cge.13199. 
646 Tate JG, Bamford S, Jubb HC, Sondka Z, Beare DM, Bindal N, Boutselakis H, Cole CG,

647 Creatore C, Dawson E, Fish P, Harsha B, Hathaway C, Jupe SC, Kok CY, Noble K, Ponting

648 L, Ramshaw CC, Rye CE, Speedy HE, Stefancsik R, Thompson SL, Wang S, Ward S,

649 Campbell PJ, Forbes SA. 2019. COSMIC: The Catalogue Of Somatic Mutations In Cancer.

$650 \quad$ Nucleic Acids Research 47:D941-D947. DOI: 10.1093/nar/gky1015.

651 Thorvaldsdóttir H, Robinson JT, Mesirov JP. 2013. Integrative Genomics Viewer (IGV): High-

652 performance genomics data visualization and exploration. Briefings in Bioinformatics

$653 \quad$ 14:178-192. DOI: 10.1093/bib/bbs017.

654 Tsongalis GJ, Peterson JD, De Abreu FB, Tunkey CD, Gallagher TL, Strausbaugh LD, Wells

655 WA, Amos CI. 2014. Routine use of the Ion Torrent AmpliSeq ${ }^{\mathrm{TM}}$ Cancer Hotspot Panel for

656 identification of clinically actionable somatic mutations. Clinical Chemistry and Laboratory

657 Medicine 52:707-714. DOI: 10.1515/cclm-2013-0883.

658 De Unamuno Bustos B, Estal RM, Simó GP, De Juan Jimenez I, Muñoz BE, Serna MR, De

659 Miquel VA, Ros ML, Sánchez RB, Enguídanos EN, Suela SP, Estrada RB. 2017. Towards

660 Personalized Medicine in Melanoma: Implementation of a Clinical Next-Generation

661 Sequencing Panel. Scientific Reports 7:1-11. DOI: 10.1038/s41598-017-00606-w.

662 Williams H, Walsh K, Diamond A, Oniscu A, Deans Z. 2018. Validation of the Oncomine Focus

663 Panel for Next Generation Sequencing of clinical tumour samples. Virchows Archiv

664 473:489-503. DOI: 10.1007/s00428-018-2411-4.

665 Xu-Monette Z, Wu L, Visco C, Tai Y, Tzankov A, Liu W, Montes-Moreno S, Dybkaer K, Chiu

666 A, Zu Y, Bhagat G, Richards K, Medeiros L, Young K. 2012. Mutational profile and

667 prognostic significance of TP53 in diffuse large B-cell lymphoma patients treated with R- 
668 CHOP: report from an international DLBCL Rituximab-CHOP Consortium Program Study. 669 Blood 120:3986-96. DOI: 10.1182/blood-2012-05-433334. 
Figure 1

Sequencing quality metrics of the Trusight ${ }^{\circ}$ Tumor 26 panel during the validation procedure of the mutational status of KRAS, NRAS and BRAF genes.

(A) Variants detected by the reference standard method against the Trusight ${ }^{\circledR}$ Tumor 26 panel. Data are shown as percentage. (B) Cluster density and cluster passing filter quality metrics, respectively expressed in cluster per $\mathrm{mm} 2$ and percentage. (C) Read depth of detected variants, 20K represents a depth of 20000x. (D) Variant allele frequency of each gene is shown as a percentage. Data are represented as box and whisker plots with median and IQR.

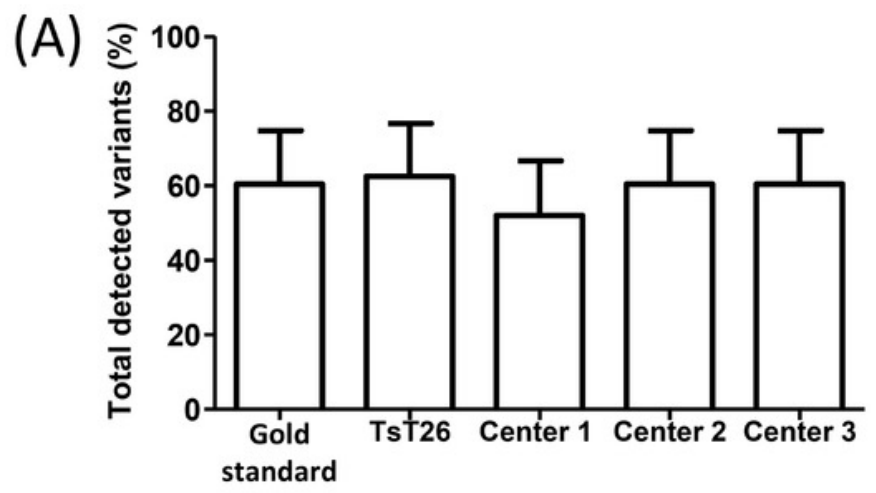

(B)

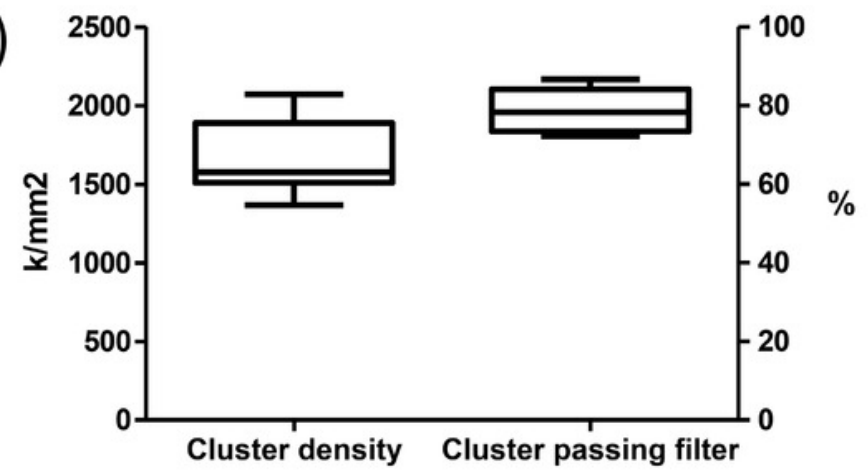

(C)

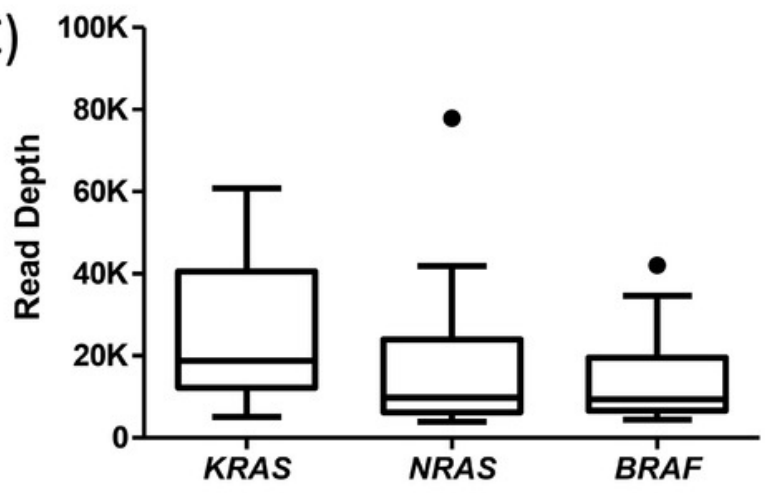

(D)

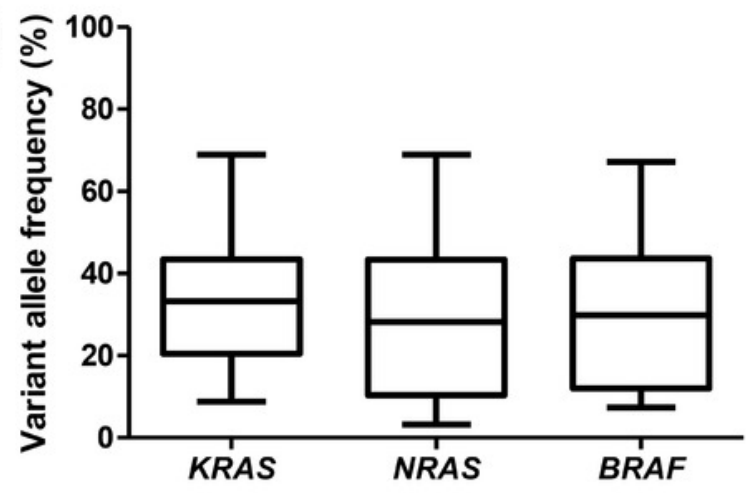




\section{Figure 2}

Practicability of the Trusight $\AA$ Tumor 26 panel.

(A) Study design of the panel performance. (B) Flow diagram depicting the number of FFPE samples that either succeded or failed to NGS testing. (C) Workflow followed by each of the 399 FFPE samples included in TsT26 panel study. Samples underwent diverse quality controls (QC). QC1 referred to the tumor-cell content; a cut off value was established in $30 \%$. Note that samples between $10-30 \%$ with no possibility of macrodissection underwent direct DNA isolation. QC2 indicated the quality of the sample in comparison to a fresh commercial preserved sample; a $\Delta C q$ value less than 6 was acceptable to continue the library preparation. QC3 determined the fragmentation of the library, library products of less than $300 \mathrm{bp}$ were not considered for sequencing (An invalid run was also used as quality control). 
(A)

1. CRC sample selection in different laboratory centers

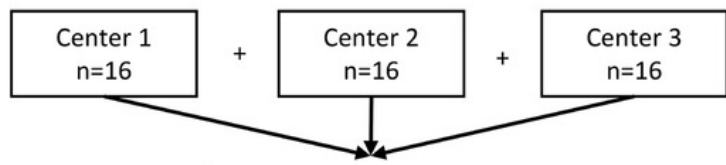

2. A total of $29 / 48$ samples affected of detected variants in KRAS, NRAS and BRAF genes and 19/48 wild-type by

conventional methods including $\mathrm{QPCR}$ and pyrosequencing

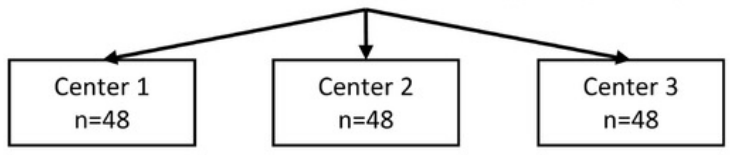

3. Testing of the 48 samples by the Trusight Tumor 26 NGSbased panel in each center

(B)

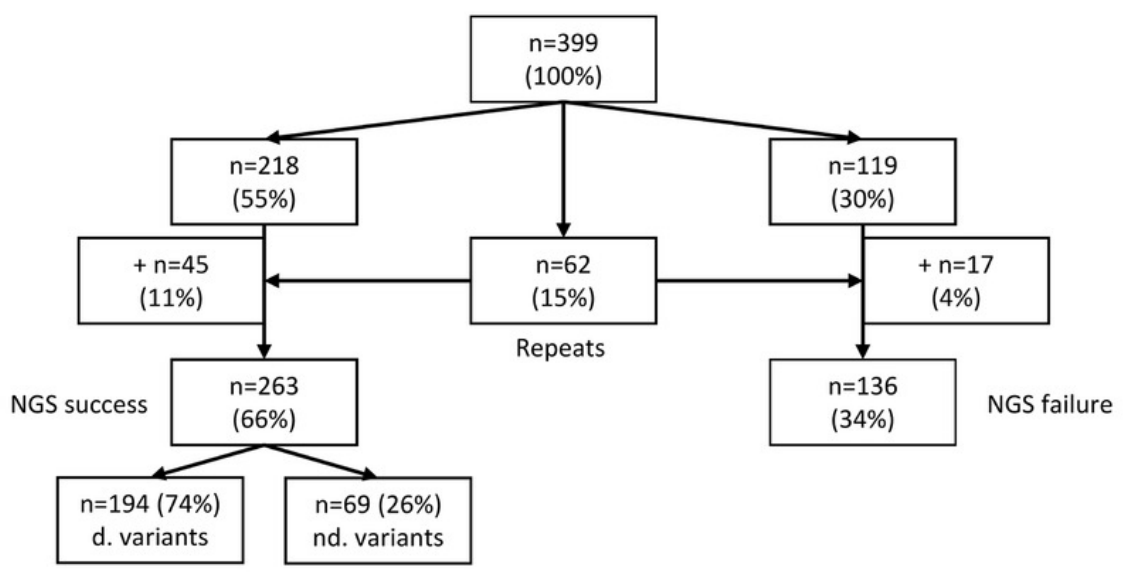

(C)

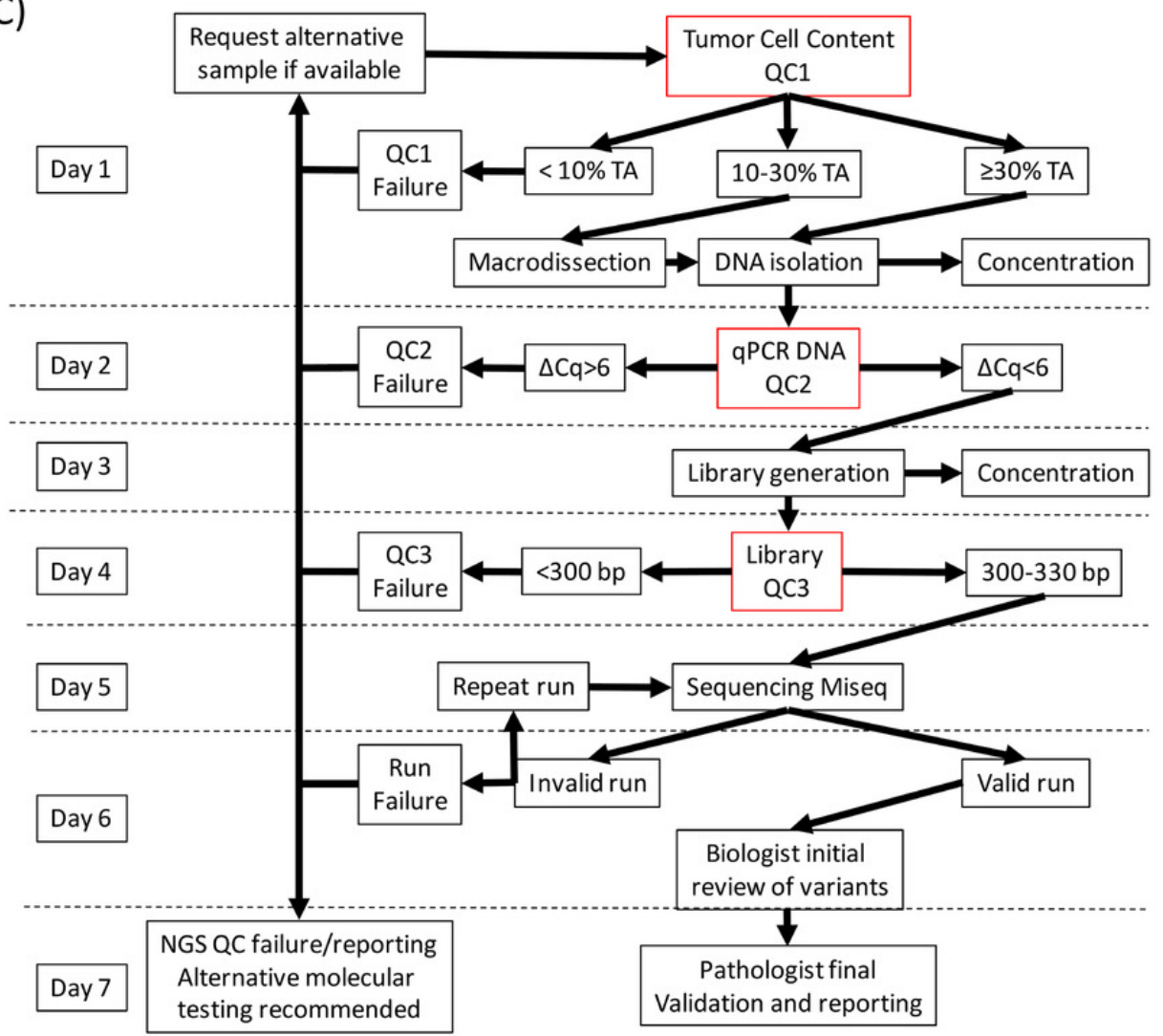




\section{Figure 3}

Sequencing quality metrics of the Trusight ${ }^{\circledR}$ Tumor 26 panel during clinical implementation.

(A) Total detected variants per gene type identified in the 399 samples tested. (B) Cluster density and cluster passing filter quality metrics respectively expressed in cluster per $\mathrm{mm} 2$ and percentage. (C) Read depth of detected variants, 20K represents a depth of 20000x. (D) Variant allele frequency of each gene is shown as a percentage. Data are represented as box and whisker plots with median and IQR. 
(A)

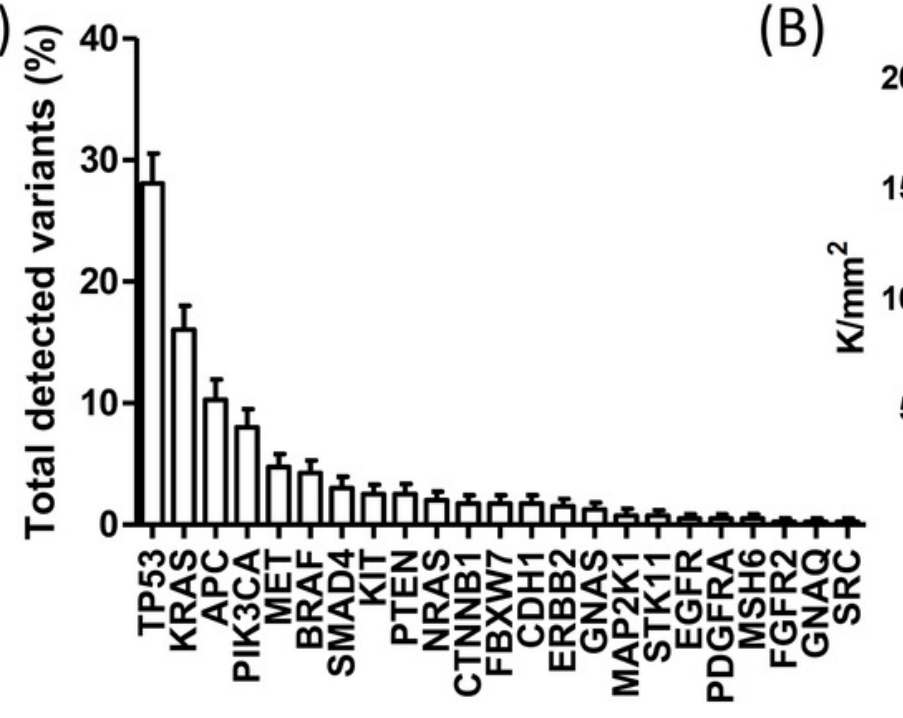

(B)

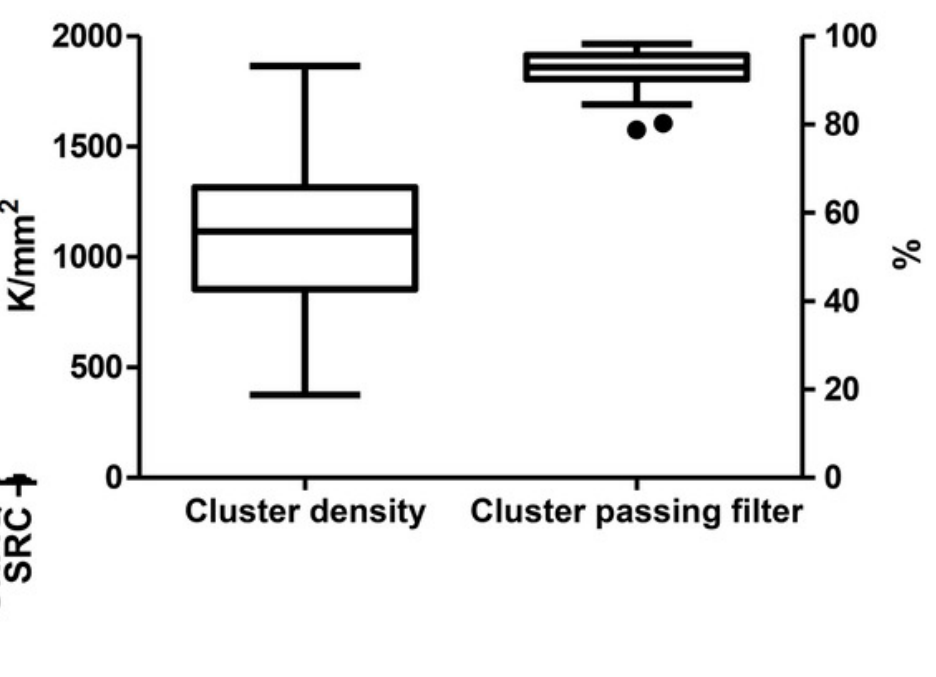

(C)

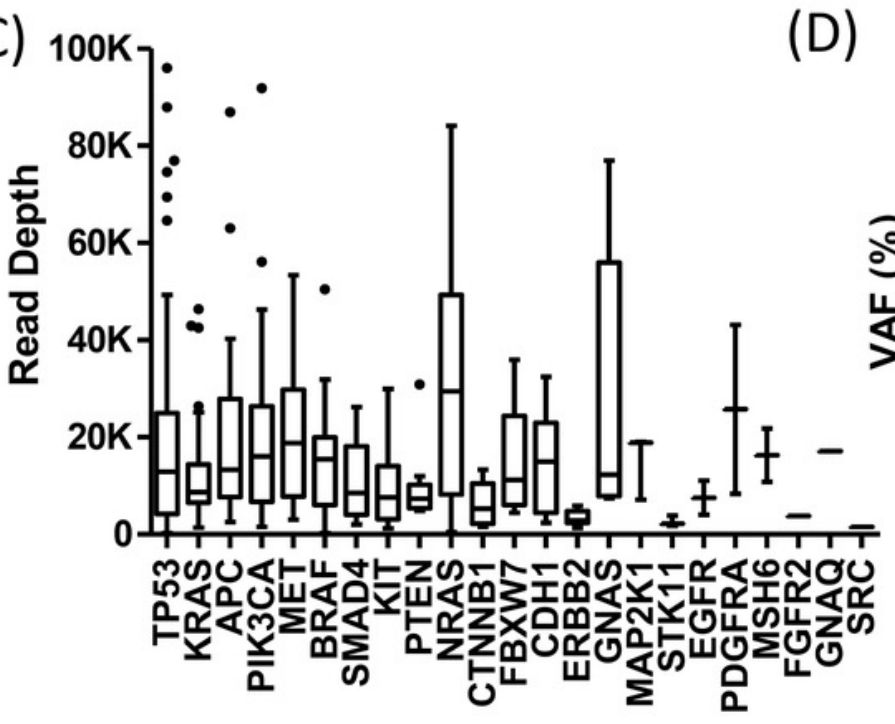

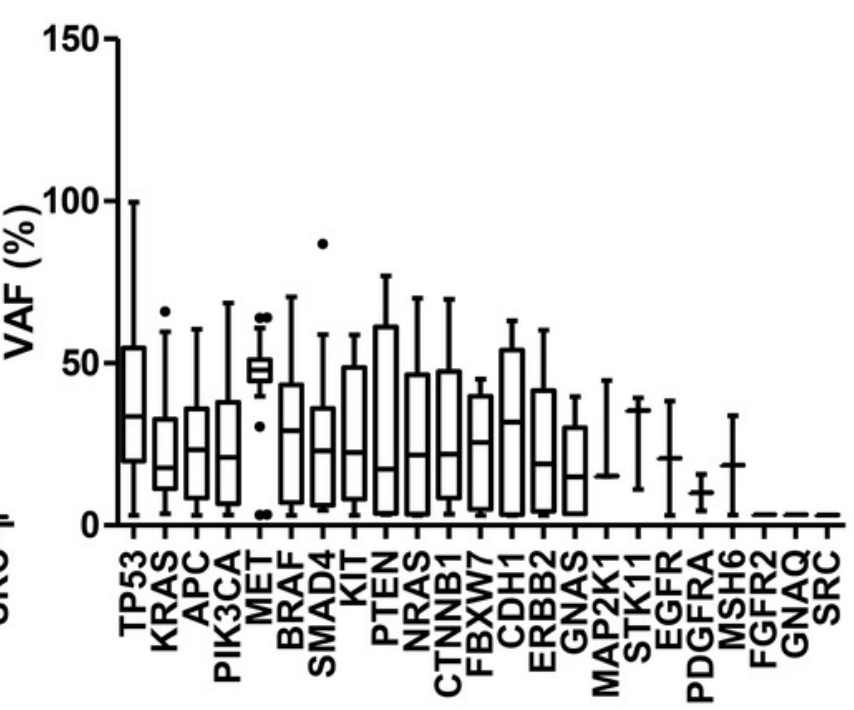


Figure 4

Detected variant frequencies across tumor types.

(A) Gastrointestinal. (B) Hematologic malignancies. (C) Lung. (D) Gynecological. Columns represent samples and rows genes indicated by percentage of samples with detected variants in a precise gene. Detected variants are shown by grey squares whereas more than one detected variant is depicted by black squares.

(A)

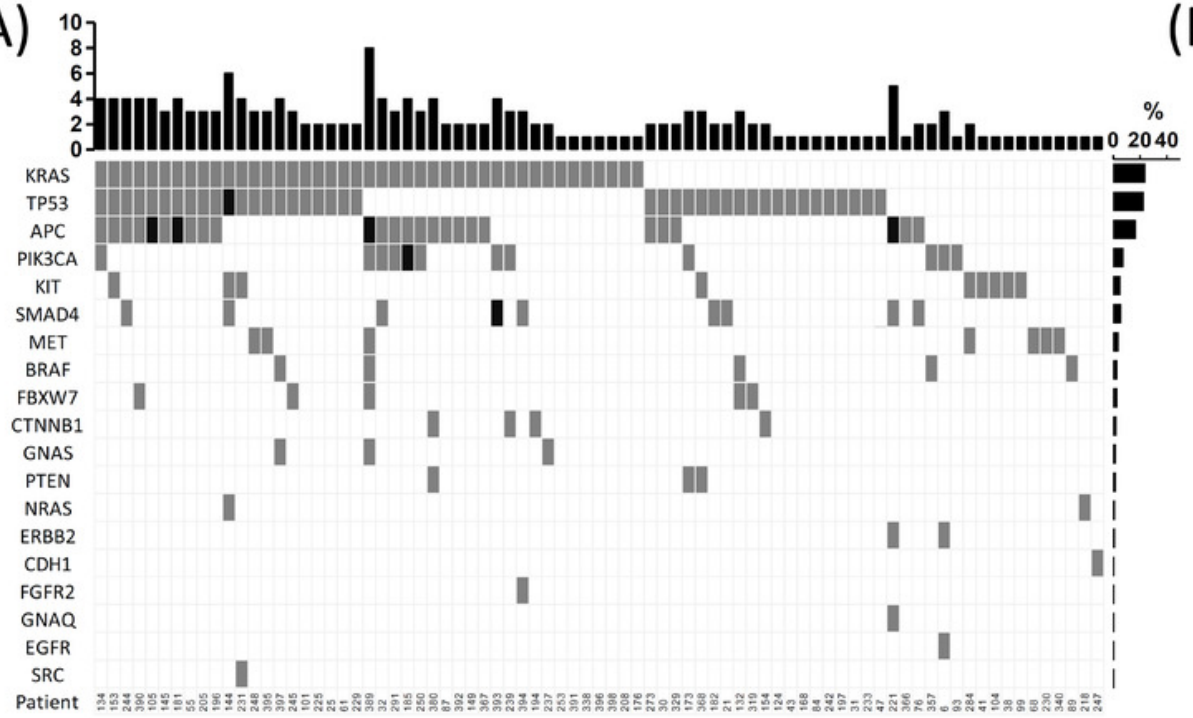

(B)

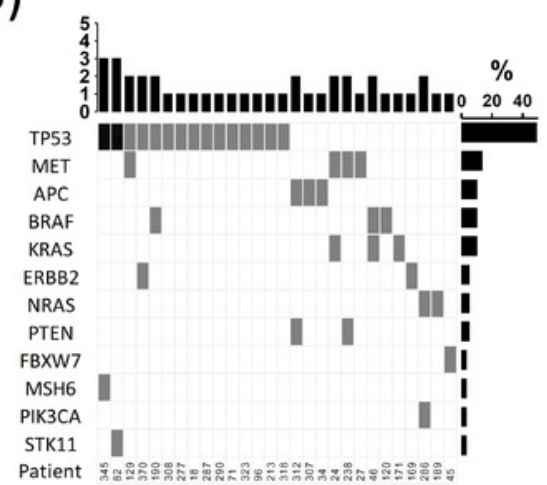

(C)

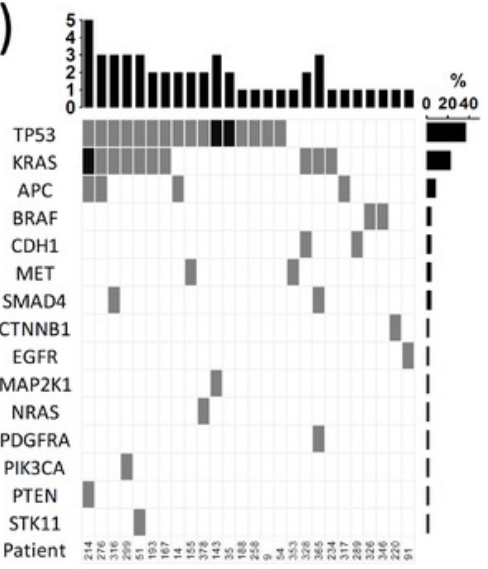

Detected variant in one gene

More than one detected variant in the same gene
(D)

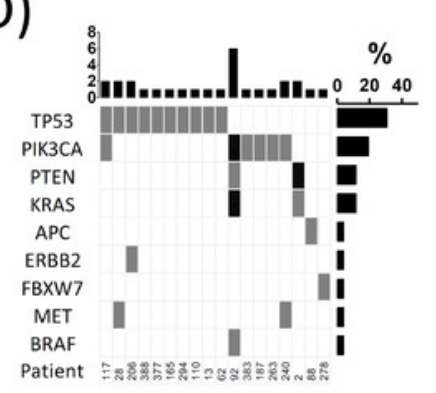




\section{Table $\mathbf{1}$ (on next page)}

Trusight $\AA$ Tumor 26 assay exon coverage by amplicons ( 82 exons from 26 genes were covered by 178 amplicons). 


\begin{tabular}{|c|c|c|c|}
\hline Gene symbol & Accession Number & Exons covered & $\begin{array}{c}\text { Number of amplicons } \\
\text { to exon coverage }\end{array}$ \\
\hline AKT1 & NG_012188.1 & 2 & 1 \\
\hline$A L K$ & NG_009445.1 & 23 & 1 \\
\hline$A P C$ & NG_008481.4 & $15^{*}$ & 14 \\
\hline$B R A F$ & NG_007873.3 & 11,15 & 3 \\
\hline $\mathrm{CDH} 1$ & NG_008021.1 & $8,9,12$ & 6 \\
\hline CTNNB1 & NG_013302.2 & 2 & 2 \\
\hline$E G F R$ & NG_007726.3 & $18,19,20,21$ & 7 \\
\hline ERBB2 & NG_007503.1 & 20 & 2 \\
\hline FBXW7 & NG_029466.2 & $7,8,9,10,11$ & 13 \\
\hline FGFR2 & NG_012449.2 & 6 & 2 \\
\hline FOXL2 & NG_012454.1 & 1 & 1 \\
\hline GNAQ & NG_027904.2 & $4,5,6$ & 6 \\
\hline GNAS & NG_016194.2 & 6,8 & 2 \\
\hline KIT & NG_007456.1 & $9,11,13,17,18$ & 9 \\
\hline KRAS & NG_007524.1 & $1,2,3,4$ & 8 \\
\hline MAP2K1 & NG_008305.1 & 2 & 1 \\
\hline MET & NG_008996.1 & $1,4,13,15,16,17,18,20$ & 22 \\
\hline MSH6 & NG_007111.1 & 5 & 3 \\
\hline NRAS & NG_007572.1 & $1,2,3,4$ & 8 \\
\hline PDGFRA & NG_009250.1 & $11,13,17$ & 5 \\
\hline PIK3CA & NG_012113.2 & $1,2,7,9,20$ & 15 \\
\hline PTEN & NG_007466.2 & $1^{\#}, 2,3,4,5^{\#}, 6^{\#}, 7,9$ & 17 \\
\hline SMAD4 & NG_013013.2 & 8,11 & 5 \\
\hline$S R C$ & NG_023033.1 & 10 & 2 \\
\hline STK11 & NG_007460.2 & $1,4,6,8$ & 7 \\
\hline TP53 & NG_017013.2 & $2^{\&}, 3^{\&}, 4^{\&}, 5^{\&}, 6^{\&}, 7,8^{\&}, 9^{\&}, 10,11$ & 16 \\
\hline
\end{tabular}

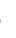

* exon 15 of the $A P C$ gene was split into 3 regions and each covered respectively by 2, 2 and 10 amplicons.

\#exons 1,5 and 6 of the PTEN gene were split into 2 regions each and separately covered by 2,2 and 2 amplicons. \&exons 2, 3 and 4 of the TP53 gene were together covered by 6 amplicons; as well as exons 5 and 6,8 and 9 , respectively by 4 and 3 amplicons. 
Table 2 (on next page)

TsT26 panel performance by determining the mutational status ofKRAS, NRASandBRAFgenes 


\begin{tabular}{cccc} 
& \multicolumn{3}{c}{ Gold standard } \\
\cline { 2 - 4 } TsT26 & $\begin{array}{c}\text { Detected } \\
\text { variant }\end{array}$ & Not detected variant & Total \\
\hline Detected variant & 80 & 3 & 83 \\
Not detected variant & 7 & 54 & 61 \\
Total & 87 & 57 & 144 \\
Sensitivity & $92 \%(80 / 87,95 \% \mathrm{Cl}=84-97)$ & \\
Specificity & $95 \%(54 / 57,95 \% \mathrm{Cl}=85-99)$ & \\
Accuracy & $93 \%(134 / 144,95 \% \mathrm{Cl}=88-97)$ & \\
Positive predictive value & $96 \%(80 / 83,95 \% \mathrm{Cl}=90-99)$ & \\
Negative predictive value & \multicolumn{2}{c}{$88 \%(54 / 61,95 \% \mathrm{Cl}=79-94)$} & \\
\hline
\end{tabular}

1

2

3

4

5

6

7

8

9

10

11

12

13

14

15

16

17

18

19

Peer] reviewing PDF | (2020:06:50245:2:0:NEW 5 Sep 2020) 
Table 3 (on next page)

Clinical and patient characteristics 


\begin{tabular}{lccccc} 
Characteristics & $\begin{array}{c}\text { Number of } \\
\text { patients }\end{array}$ & Cytology & Resection & Endoscopy & Biopsy \\
\hline Sex, no. (\%) & & & & & \\
Female & $188(49)$ & & & \\
Male & $198(51)$ & & & & \\
Mean age, y.o. & $59(58-61)$ & & & & \\
$\begin{array}{l}\text { (95\%Cl)* } \\
\text { Tumor type, no. (\%) }\end{array}$ & & & & & \\
Gastrointestinal & $115(29)$ & 0 & $35(30)$ & $23(20)$ & $57(50)$ \\
Hematologic & $73(18)$ & 0 & $12(16)$ & 0 & $61(84)$ \\
Lung & $51(13)$ & $13(25)$ & $6(12)$ & 0 & $32(63)$ \\
Gynecologic & $38(8)$ & 0 & $14(34)$ & $1(3)$ & $23(63)$ \\
Breast & $33(8)$ & $2(6)$ & $9(27)$ & $1(3)$ & $21(64)$ \\
Genitourinary & $20(5)$ & 0 & $9(47)$ & 0 & $11(53)$ \\
Head and Neck & $19(5)$ & 0 & $6(32)$ & 0 & $13(68)$ \\
Melanoma & $15(4)$ & $1(7)$ & $3(20)$ & 0 & $11(73)$ \\
Central Nervous System & $10(3)$ & 0 & $3(30)$ & 0 & $7(70)$ \\
Other solid tumor & $25(6)$ & $1(4)$ & $3(12)$ & 0 & $21(84)$ \\
\hline
\end{tabular}

* Sex and age data was not available for every patient included in the study

2

3 
Table 4 (on next page)

DNA quality assessment by quantitative PCR 


\begin{tabular}{lccc} 
& $\Delta \mathrm{Ct}<4$ & $4<\Delta \mathrm{Ct}<6$ & $\Delta \mathrm{Ct}>6$ \\
\hline Detected variant & $159(40 \%)$ & $19(5 \%)$ & $3(1 \%)$ \\
Not detected variant & $59(15 \%)$ & $5(1 \%)$ & $2(1 \%)$ \\
NGS fail & $26(6 \%)$ & $27(7 \%)$ & $62(15 \%)$ \\
\hline
\end{tabular}

1

2

3

4 